\title{
ACTIVITIES OF THE RESEARCH DIVISION ON PHILOSOPHY AND PRINCIPLES OF PHYSICAL EDUCATION IN 1975-76
}

\author{
Yasuki Kato \\ Tokyo University of Education
}

1. Symposia at the Annual Convention of J.S.P.E.

This Research Division has been holding a symposium as a part of the program in the Annual Convention of J.S.P.E. since 1962. Themes of the symposia held 1975 and 76 were as follows :

1975 : Relationship between Physical Education and Sport.

1976 : The Fundamental Study of Physical Education and Sport.

In these years, this Division selected the principal subject and discussed it on the interdisciplinally and relativistic standpoints. Namely, in the former year, this Division took it up with the standpoint of socialism, capitalism in England, and in Japan, with the standpoints of teacher and learner.

2. Presentation of Individual Reserch Reports in the Annual Convention of J.S.P.E.

In recent years, a large number of interesting papers on the results of the survey have been presented. The number of the papers in this section were 36 (6.2\% of the total presentation) in 1975 , and $26(5.1 \%)$ in 1976.

3. Publications

This Research Division has published a book as a part of a series in this area in the last two years as follows :

Vol. X (1976) Theory of Esthetics in Sport.

(Tokyo; Fumai-do Publishing Company)

4. The Monthly Meetings

Besides the regular members, a few professors were invited every month as guest speakers for discussion of philosophy and principles of physical education. Themes of the monthly meetings in these years were specified as follows:

1975 : (1) Methodology of Ethics.

(2) About the Bioecological-Ethical Method (parts 1 and 2).

(3) School Physical Education in Germany.

(4) The Present Status and Problems of Research of Physical Education in the West Germany.

(5) The Main Thought of Revision on the Education Course.

1976 : (1) About the Scientific-Ethical Method.

(2) The Trend and Contents of International Conventions. 
(3) The Result and Subject of Logics.

(4) Circumstances of School Physical Education in Poland.

(5) The Therapeutic Recreation in U.S.A.

(6) The Modal Logics.

(7) Problems of the Method at the Point of Scientific History.

(8) Problems of the Method at the Point of Philosophy (parts 1 and 2).

(9) A Question to the Classical (17-19 Centuy) Methodology.

\section{Contents of Summer Seminar}

The Research Division of Philosophy and Priciples of Physical Education holds a seminar every summer. The contents of the seminar in 1975 and 1976 was as follows:

1975 : (1) The Formation of Modern Sport-particularly in Focus on Gentleman Ideal in English Sport-.

(2) A Historical Study of the Meaning of Physical Eduation and Sport.

(3) How to Conceive Physical Education and Sport.

(4) Interrelation between Physical Education and Sport.

(5) Physical Education and Sport in Law.

(6) An Introduction of the Analysis of the Claim that Physical Education has a "Family Resemblance" Term.

(7) About Physical Education and Sport in Focus on School Physical Education.

(8) Some Thought in Physical Education and Sport.

Symposium : Relation between Physical Education and Sport.

1976 : (1) The Concept of Physical Education in America.

(2) From Attending "The International Science Council of Physical Movement."

(3) About the Fundamental Bibliography Relevant to the Theory of Esthetics in Sport.

(4) Esthetic Characteristics of Sport in Japan.

(5) Esthetic Characteristics of Sport in D.D.R.

(6) What is Beauty of Sport?

(7) The Principle of Sport Coaching.

(8) Characteristics of Japanese Budo.

(9) Problems in Relation between Physical Education and "Body and Mind."

(10) The Last Subjects of Physical Education.

(11) The Interrelation of Body and Mind in Yoga.

Symposium : The Fundamental Study of Physical Education and Sport. 